\title{
A pyrolysis mass spectrometry study of the non-pigmented Prevotella species
}

\author{
J. T. MAGEE* , R. YOUSEFI-MASHOUF $\ddagger, J . M$. HINDMARCH $\dagger$ and B. I. DUERDEN $\ddagger$
}

Department of Microbiology, The Children's Hospital, Sheffield S10 2TH, †Bacteriology Department, Royal Hallamshire Hospital, Sheffield S10 2JF and $\ddagger$ Department of Experimental and Clinical Microbiology, University of Sheffield Medical School, Sheffield S10 2RX

\begin{abstract}
Summary. Collection strains (21) and non-pigmented clinical isolates (96) provisionally identified as Prevotella spp. were classified numerically on the basis of pyrolysis mass spectrometry (PMS) data and reaction patterns in conventional tests (CTRPs) for volatile and non-volatile fatty acids, pre-formed enzymes and biochemical activity. PMS and CTRP classifications were compared with a previous classification based on visual analysis of SDSPAGE patterns. Although the order of clusters differed, cross-tabulation of cluster membership revealed strong correlations between classifications. Cluster membership in the PMS classification correlated particularly well with SDS-PAGE results. CTRP clusters corresponded largely to the recognised species of Prevotella, but PMS and SDS-PAGE divided two species into sub-groups: two in $P$. buccae and five in $P$. veroralis. The latter subgroups could be discriminated by small but consistent differences in CTRPs. An undesignated, well differentiated cluster of strains appeared closest to the main group of $P$. buccae strains in PMS and CTRPs. B. (P.) capillus could not be distinguished from P. buccae; these species are regarded as synonymous. Strains of $P$. zoogleoformans and $B$. ( $P$.) pentosaceus were well separated from other strains in PMS. A complex comprising clusters of $P$. disiens, $P$. oralis, $P$. veroralis, $P$. loescheii and a further undesignated group similar to $P$. melaninogenica was well differentiated from $P$. buccae and $P$. oris in PMS; clusters corresponding to $P$. bivia, $P$. corporis, $P$. intermedia and $P$. denticola formed another complex.
\end{abstract}

\section{Introduction}

Small gram-negative anaerobic bacilli of the new genus Prevotella, ${ }^{1}$ previously known as the melaninogenicus-oralis group of the genus Bacteroides, ${ }^{2}$ are important members of the normal flora of the mouth ${ }^{3-5}$ and make a significant contribution to the microbial flora of periodontal disease. ${ }^{6-9}$ They are also implicated in other infections, particularly of the urogenital tract, head, neck and lung. ${ }^{10-16}$ Prevotella spp. are moderately saccharolytic and form a coherent group that differs significantly from the emended description of the genus Bacteroides, ${ }^{17}$ which now contains only those species of the $B$. fragilis group. The blackpigmented members (formerly B. melaninogenicus) of this new genus are well known, but the non-pigmented members have received less attention.

Loesche $e t$ al ${ }^{18}$ first described oral non-pigmented gram-negative obligate anaerobes as B. oralis in 1964. Although the original type strain (ATCC 15930) was

Received 1 Aug. 1991; revised version accepted 27 Dec. 1991. * Present address: Department of Medical Microbiology and Public Health Laboratory, University of Wales College of Medicine, Heath Park, Cardiff CF4 4XN. shown to produce pigment, ${ }^{19,20}$ and was re-named $B$. loescheii ${ }^{21}$ the term $B$. oralis continued to be used for non-pigmented oral bacteroides. It became evident that these strains form part of the normal gingival crevice flora ${ }^{2,3}$ and are associated with periodontal disease and other oral infections. ${ }^{6-9}$ Similar bacteria are found in the vagina, ${ }^{22}$ where they may have a pathogenic role in conditions such as anaerobic vaginosis. ${ }^{23-26}$ The vaginal strains were distinguishable from oral strains and were given the species names $B$. bivius and $B$. disiens. ${ }^{27}$ Before the taxonomic revision of the family Bacteroidaceae, ${ }^{17}$ the oral strains were designated as various subspecies or types of $B$. oralis or $B$. ruminicola, but the revision elevated several of these to full species status. The new species include $P$. buccae and $P$. oris ${ }^{28}$ B. buccalis, ${ }^{29} P$. zoogleoformans, ${ }^{30} P$. verorali $^{31}$ and $P$. oulora. ${ }^{32}$ Two further species which might otherwise have been transferred to the genus Prevotella, $B$. (P.) capillus $^{33}$ and $B$. (P.) pentosaceus, ${ }^{29}$ showed close similarity with $P$. buccae in DNA hybridisation, and these species names are now regarded as synonymous with $P$. buccae. ${ }^{34}$

Major taxonomic revisions encourage independent work by a wide variety of techniques to amplify the descriptions of new species, to examine intra-species 
Table I. Collection strains studied

\begin{tabular}{|c|c|c|c|c|}
\hline \multirow{2}{*}{ Species } & \multirow{2}{*}{ Designation } & \multicolumn{2}{|c|}{$\begin{array}{c}\text { Cluster* } \\
\text { membership }\end{array}$} & \multirow{2}{*}{ Source } \\
\hline & & CTRP & PMS & \\
\hline P. melaninogenica & NCTC 11559‡ & A & $10 c$ & Brain abscess \\
\hline P. loescheii & ATCC $15930^{\circ}$ & $\mathrm{T}$ & 11 & Gingival crevice \\
\hline P. denticola & ATCC $35308 \dagger$ & B & $12 \mathrm{a}$ & Dental plaque \\
\hline P. bivia & VPI 5540‡ & $\mathrm{C}$ & $12 b$ & Endometrium \\
\hline P. oralis & NCTC $11459 \dagger$ & $\mathbf{F}$ & $9 a$ & Periodontal pocket \\
\hline$P$. veroralis & ATCC $33779 \dagger$ & I & 6 & Oral cavity \\
\hline P. veroralis & $83-457 \S$ & I & 7 & $\ldots$ \\
\hline P. buccalis & ATCC $35310 \dagger$ & I & 17 & Dental plaque \\
\hline P. oris & ATCC $33573 \dagger$ & $\mathbf{N}$ & $9 a$ & Gingival crevice \\
\hline P. oris & 86-201DD $\S$ & $\mathbf{M}$ & 20 & Subgingival plaque \\
\hline P. oulora & NCTC $11871 \dagger$ & $\mathbf{J}$ & 21 & Subgingival plaque \\
\hline B. $(P$.$) pentosaceus \|$ & NP $333 \dagger$ & $\mathbf{M}$ & 18 & Dental plaque \\
\hline B. (P.) pentosaceus\| & WPH 61 & $\mathbf{M}$ & 20 & Dental plaque \\
\hline P. zoogleoformans & ATCC 33285† & $\mathbf{M}$ & 19 & Oral cavity \\
\hline$P$. intermedia & NCTC $9336{ }^{\circ}$ & $\mathbf{R}$ & 22 & Vincent's angina \\
\hline$P$. corporis & ATCC $33547 \dagger$ & $\mathbf{S}$ & 13 & Cervical swab \\
\hline P. disiens & VPI 8057ף & $\mathrm{D}$ & 2 & $\ldots$ \\
\hline$P$. disiens & NCTC $11157+9$ & D & 2 & Bartholin's abscess \\
\hline P. buccae & ATCC $33574 \dagger$ & K & $3 a$ & Gingival crevice \\
\hline P. buccae & $83-617 \S$ & K & $3 a$ & $\ldots$ \\
\hline B. $(P$.$) capillus \|$ & ATCC $33690 \dagger$ & $\mathbf{K}$ & $3 a$ & Periodontal pocket \\
\hline
\end{tabular}

\footnotetext{
* Cluster membership in the PMS and CTRP dendrograms (figs. 1 and 2).

$\dagger$ Designated type strain or a clone thereof from another collection.

‡ Donated by Dr E. M. Barnes, AFRC Food Research Institute, Norwich.

$\S$ Donated by Dr S. M. Finegold, V. A. Wadsworth Medical Center, California.

\|I These species have been suggested to be synonymous with $P$. buccae.

I VPI 8057 and NCTC 11157 are the same clone from different collections.
}

homogeneity and inter-species discrimination, and to explore pathogenic and ecological properties. In previous studies of the non-pigmented Prevotella ${ }^{35,36}$ we found several areas of disagreement with the current classification of the genus. In particular, two clusters of strains could not be equated with any currently recognised species in CTRPs ${ }^{35}$ nor SDS-PAGE. ${ }^{36}$ Further, strains of two species, $P$. buccae and $P$. veroralis, appeared heterogenous, dividing into two and five subgroups, respectively, on the basis of SDSPAGE. $^{36}$

Here, we describe further work in which numerical classifications based upon (i) compositional characters, assessed in pyrolysis mass spectrometry ${ }^{37,38}$ (PMS), and (ii) conventional test reaction patterns (CTRPs) are compared. These results are further compared with those of our previous studies and the currently accepted classification of the genus. Further strains, included reference strains of the pigmented species, have been added to the collection of strains examined.

\section{Materials and methods}

\section{Bacterial strains}

The strains studied comprised 21 from collections (table I), and 96 clinical isolates from 21 adults with periodontal disease. All were checked for purity on BM-KV agar, ${ }^{8,39}$ incubated anaerobically $\left(\mathrm{H}_{2}, 10 \%\right.$, $\mathrm{CO}_{2}, 10 \%, \mathrm{~N}_{2}, 80 \%$ ) for $72 \mathrm{~h}$ at $37^{\circ} \mathrm{C}$ and stored at $-70^{\circ} \mathrm{C}$ as suspensions in Nutrient Broth (Oxoid) containing inactivated horse serum (Wellcome) $10 \%$ and glucose $1 \%$. They were subsequently characterised in the combination of conventional, enzyme, gas-liquid chromatographic (GLC) and SDS-PAGE tests described previously ${ }^{35,36}$ and summarised briefly below. The clinical isolates were identified and assigned to named species according to the scheme described previously. ${ }^{40}$

\section{Characterisation in conventional tests}

The tests of biochemical and other phenotypic characters comprised: colony size, buffy or gloss appearance, adhesion to the medium, pigmentation and fluorescence under UV light; production of indole; hydrolysis of aesculin, starch, hippurate and $o$ nitro-phenyl galactoside; production of acid from arabinose, xylose, rhamnose, glucose, lactose, sucrose, maltose, cellobiose, salicin, inulin and xylan; resistance to neomycin, kanamycin, penicillin and rifampicin; and tolerance of Victoria Blue 4R, gentian violet and sodium taurocholate. Enzyme tests comprised those for $\beta$-xylosidase, $\beta$-glucuronidase, $\beta$ glucosidase, $\alpha$-glucosidase, $\alpha$-galactosidase, $\alpha$-fucosidase, $\beta$ - $\mathrm{N}$-acetyl-glucosaminidase and $\alpha$-mannosidase, by reagent tablets ${ }^{41}$ (Rosco Diagnostic Lab M).

Gas-liquid chromatography for volatile and nonvolatile fatty acids was performed on cultures after growth in Fastidious Anaerobe Broth (Lab M) for $72 \mathrm{~h}$ at $37^{\circ} \mathrm{C} .{ }^{35}$ Production of acetic, propionic, iso-valeric, 


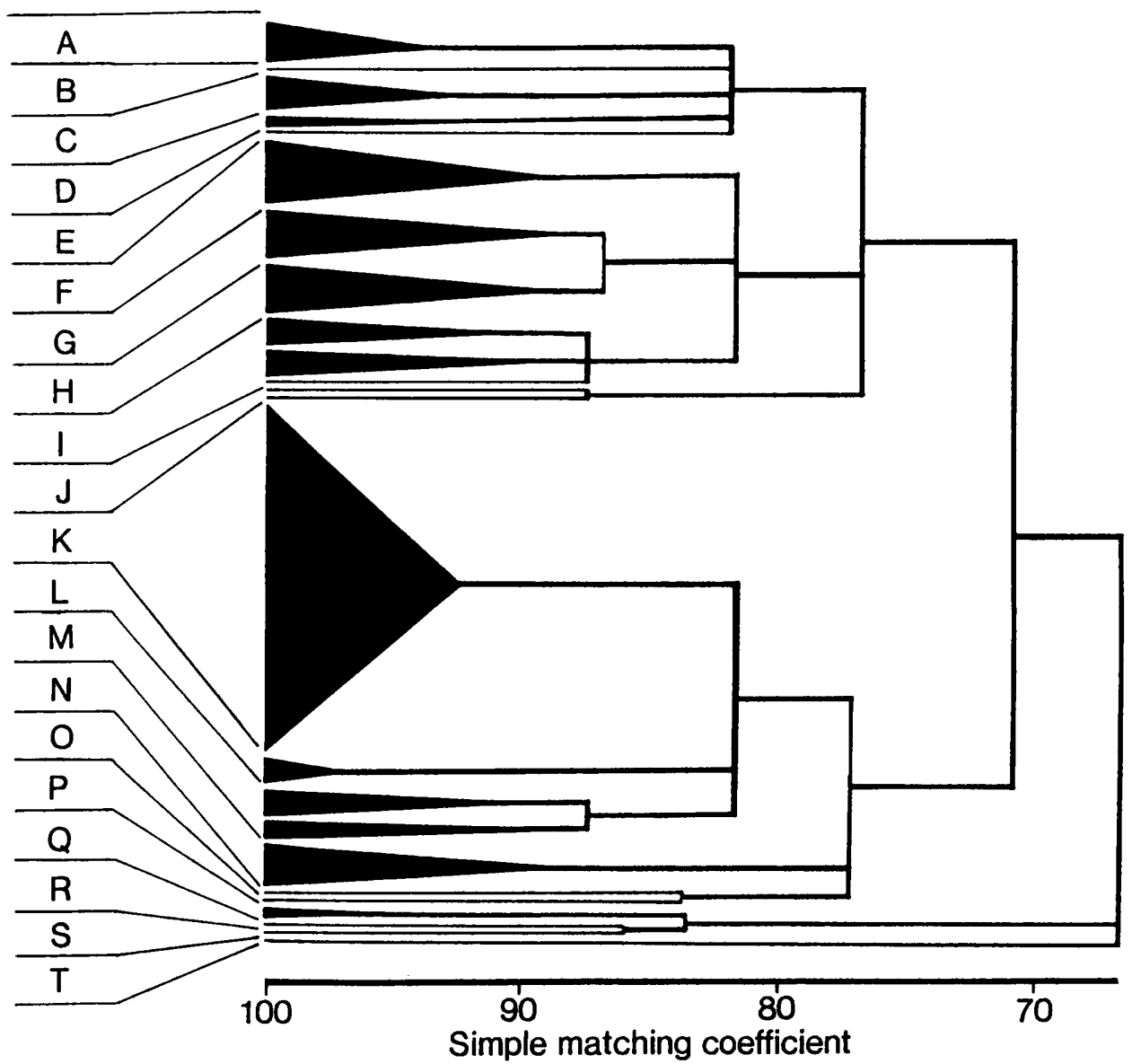

Fig. 1. A dendrogram representing inter-strain similarities and clustering based on conventional test reaction patterns. Major equivalencies to species (for further details see Results and tables I and III; inclusion of the type strain is indicated by*): A, $P$. melaninogenica*; B, $P$. denticola* $^{*} \mathbf{C}, P$. bivia*; $;$, P. disiens*; E, undesignated IXa $; \mathbf{F}, P$. oralis*; $;$, $P$. veroralis $\mathrm{A}$ C and $\mathrm{E} ; \mathrm{H}, P$. veroralis $\mathrm{A}$ and $\mathrm{D} ; \mathrm{I}, P$. veroralis* B and $P$. buccalis $* \mathbf{J}, P$. oulora* $* \mathbf{K}, P$. buccae* and $P$. (B.) capillus* $; \mathbf{L}$, undesignated $\mathrm{IIb} ; \mathbf{M}, \mathbf{N}^{*} \mathbf{O}$ and $\mathbf{P}, P$. oris $; \mathbf{Q}$ and $\mathbf{R}^{*}, P$. intermedia; S, P. corporis*, T, P. loescheii*.

iso-butyric, $n$-butyric, pyruvic, lactic, succinic and phenylacetic acids were recorded as two binary $(+/-)$ characterisation variables for each acid, the first indicating detection and the second indicating production of large amounts of the acid. Results for an unidentified metabolite eluting with the non-volatile fatty acids at a retention time of $15-16$ min were also recorded.

\section{Pyrolysis mass spectrometry}

For each culture, four replicate spectra were obtained from analyses with a Horizon Instruments PYMS 200X automated pyrolysis mass spectrometer (Horizon Instruments, Heathfield, Sussex). Methods and mathematical data processing were as described previously. ${ }^{42,43}$ Briefly, colony material was smeared on to pyrolysis foils and dried at $80^{\circ} \mathrm{C}$ for $10 \mathrm{~min}$. The foils, in tubes, were loaded in the magazine of the PYMS 200X, where they were transferred sequentially to the pyrolysis area by an automated sample handler. Here, the tube was evacuated, and the foil was heated to its Curie point $\left(530^{\circ} \mathrm{C}\right)$ for $4 \mathrm{~s}$ by electromagnetic induction. Pyrolysis products from the sample diffused into the quadrupole mass spectrometer, where they were ionised and separated according to mass:charge ratio. The resulting spectrum, showing the number of ions detected for unit mass intervals from 11 to 200, was stored on floppy disk.

The spectra contain a large amount of information with a complex statistical structure, and subsequent processing is designed to express the inter-strain spectrum differences in a small number of derived variables of less complex structure, known as canonical discriminant function co-ordinates (CDFCs), obtained from inter-strain discriminant analysis. In this, the four spectra of each strain contribute to an estimate of the pattern of variation expected for replicate spectra of a single sample. This allows estimation of the statistical significance of inter-strain spectrum differences, expressed as a "distance". Finally, the "distances" between strains are expressed as CDFCs for each strain, such that the sum of the squares of the differences, or squared Euclidean distance, between CDFCs for any pair of strains is the $\chi^{2}$ probability that the spectra of the two strains differed significantly.

\section{Numerical classifications}

Classification analyses were as described previously ${ }^{43}$ Briefly, similarity coefficients were the simple 


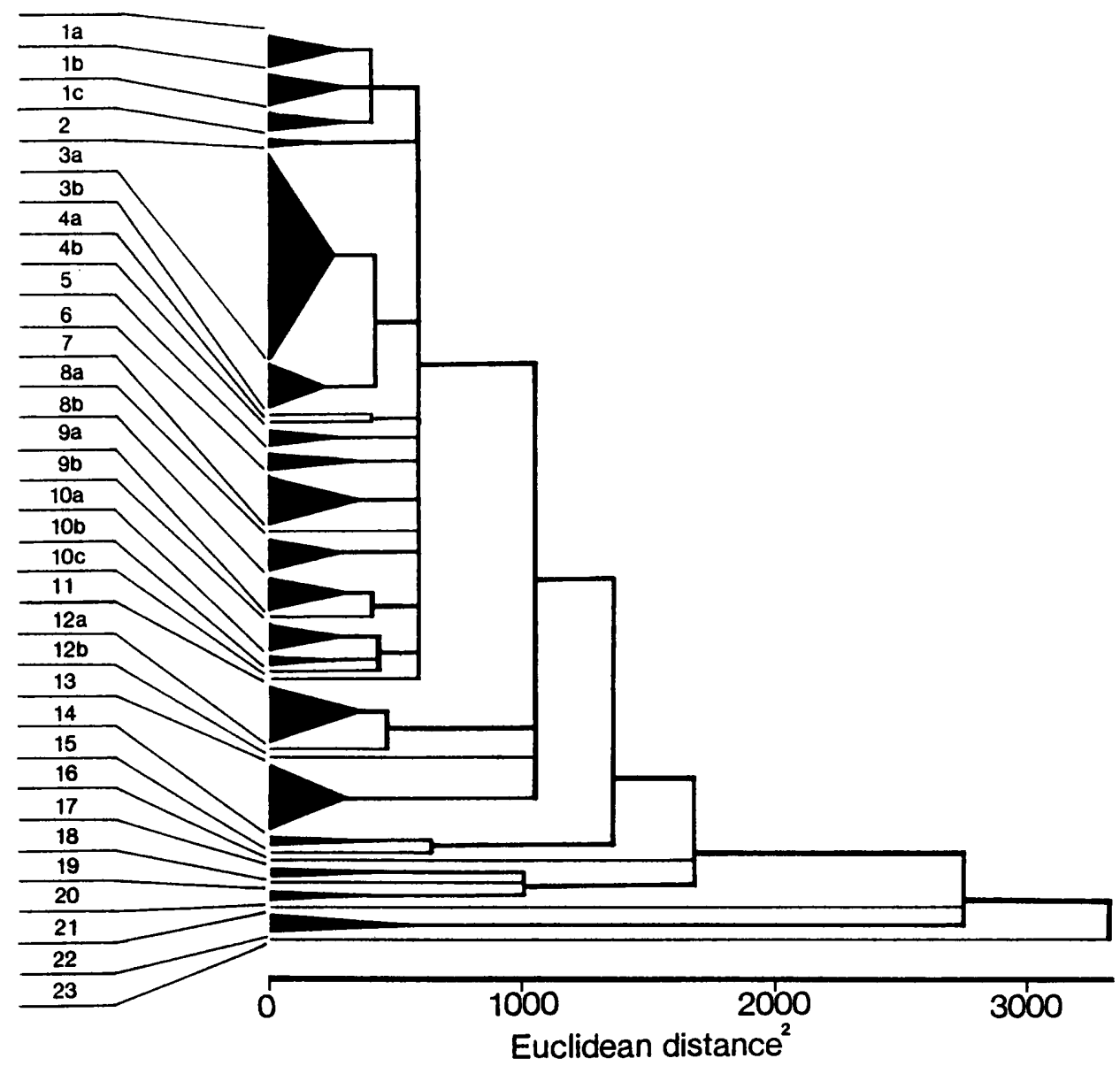

Fig. 2. A dendrogram representing inter-strain similarities and clustering based on PMS. The dissimilarity index (Euclidian distance ${ }^{2}$ ) approximates to $\chi^{2}(24$ dof $)$ probability that strains yielded indistinguishable spectra, with a value of 50 equivalent to $p=0.001$. Equivalence of groups to species are given in the text and table I and III.

matching coefficient for CTRP data and squared Euclidean distance for PMS data; hierarchical clustering was by the unweighted pair-group method with averages(UPGMA). Cross-tabulations of cluster membership in these classifications were examined; clusters were re-ordered to optimise matching along a diagonal of correlated cluster membership (table II) reflecting the inter-strain similarities found in both CTRPs and PMS. To prevent subjective bias, the identities of coded strains were not revealed until this cross tabulation was finalised. Results were also expressed as an ordination diagram of the first three CDFCs, portraying $c .54 \%$ of the statistically significant interstrain variation in PMS (figs. 3 and 4).

\section{Results}

Dendrograms obtained for CTRP and PMS data are shown in figs. 1 and 2 respectively. The tight correlations between these classifications are shown in the cross-tabulation of cluster membership in table II, and CTRPs for the clusters discussed below are detailed in table III. The ordination diagrams (figs. 3 and 4) show similarities in PMS as scatter diagrams in three dimensions on statistically corrected axes which illustrate c. $54 \%$ of the inter-strain discrimination achieved. Fig. 3 shows results for all groups, and fig. 4 shows a more detailed view for mean group points in the oralis-veroralis (OV) complex (see below).

\section{Broad divisions of the genus}

Strain points in fig. 3 formed four distinct complexes; (i) the OV complex at the mid-right, comprising strains of $P$. oralis, $P$. veroralis, $P$. disiens, $P$. buccalis, $P$. melaninogenica and $P$. loescheii, with strains of $P$. oris and $P$. oulora as outliers; (ii) the "buccae complex" comprising three tight clusters at the front left, corresponding to $P$. buccae plus $B$. $(P$.) capillus and an undesignated group; (iii) the DB complex at the rear left comprising clusters of $P$. denticola, $P$. bivia and $P$. corporis with $P$. intermedia as an outlying group; and (iv) the ZP complex, a scattered series of points corresponding to strains of $P$. zoogleoformans and $B$. $(P$.) pentosaceus at the mid-left.

This separation correlated with the behaviour of strains in protein extraction for SDS-PAGE. OV complex strains were difficult to lyse; those of the DB and ZP complexes were more susceptible, and strains of the buccae complex lysed almost immediately. This may imply differences in wall structural components, affecting both lysis and cell composition. 
Table II. Cross-tabulation of group membership in the CTRP and PMS classifications

\begin{tabular}{|c|c|c|c|c|c|c|c|c|c|c|c|c|c|c|c|c|c|c|c|c|c|}
\hline \multirow{2}{*}{$\begin{array}{l}\text { PMS } \\
\text { cluster }\end{array}$} & \multicolumn{20}{|c|}{ CTRP cluster } & \multirow{2}{*}{ Species* } \\
\hline & A & $\mathrm{T}$ & B & $\mathrm{C}$ & I & $\mathrm{J}$ & $\mathrm{H}$ & G & $\mathrm{D}$ & $\mathrm{F}$ & $\mathrm{N}$ & O & $\mathbf{P}$ & $\mathrm{E}$ & L & $\mathbf{K}$ & $\mathbf{M}$ & Q & $\mathbf{R}$ & $\mathbf{S}$ & \\
\hline $\begin{array}{c}1 \mathrm{a} \\
10 \mathrm{c} \\
11 \\
12 \\
6 \\
4 \mathrm{~b} \\
17 \\
21 \\
10 \mathrm{~b} \\
10 \mathrm{a} \\
1 \mathrm{~b} \\
1 \mathrm{c} \\
2 \\
8 \mathrm{a} \\
5 \\
9 \mathrm{a} \\
8 \mathrm{~b} \\
15 \\
16 \\
7 \\
3 \mathrm{a} \\
3 \mathrm{~b} \\
4 \mathrm{a} \\
9 \mathrm{~b} \\
14 \\
23 \\
18 \\
19 \\
20 \\
22 \\
13\end{array}$ & $\begin{array}{l}4 \\
1 \\
1\end{array}$ & 1 & 1 & 5 & $\begin{array}{l}3 \\
3 \\
1 \\
1 \\
1\end{array}$ & $\begin{array}{l}1 \\
1\end{array}$ & $\begin{array}{l}1 \\
1 \\
2 \\
1\end{array}$ & $\begin{array}{l}3 \\
4 \\
2\end{array}$ & 2 & $\begin{array}{l}1 \\
3 \\
4 \\
1\end{array}$ & $\begin{array}{l}1 \\
3 \\
2\end{array}$ & 1 & 1 & 1 & 4 & $\begin{array}{r}1 \\
27 \\
7 \\
1 \\
1 \\
8\end{array}$ & $\begin{array}{l}1 \\
2 \\
1 \\
2\end{array}$ & 2 & 1 & 1 & 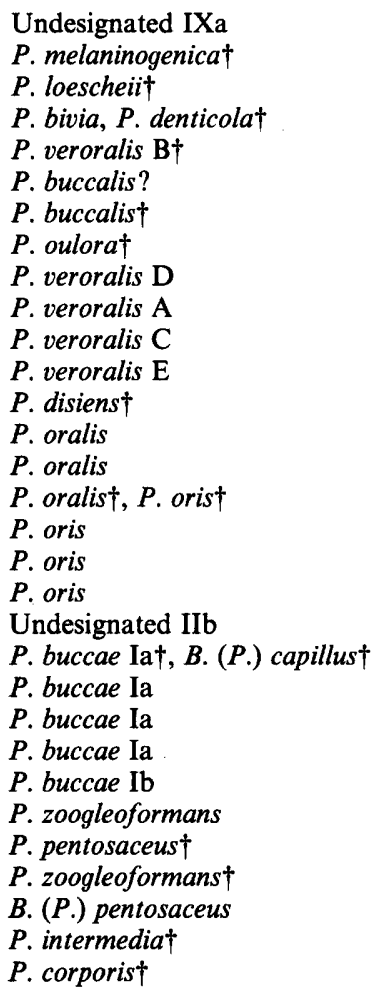 \\
\hline
\end{tabular}

* Equivalence between these group designations, and those used in previous work are as follows, with the CTRP group letter in this study, followed by group designations in the conventional identification study ${ }^{35}$ and in the SDS-PAGE study ${ }^{36}: A, J$ and IXA; C, I and VIII; E, J and IXB; F, E and IV; G, F and V; H, F and V; I, J F G and IXB V VI; J, H and VII; K, A and IA IB; L, C and IIb, M, B and IIA; N $O P, B$ and III. Strains of CTRP clusters B, Q, R, S and T were not included in previous studies.

$\dagger$ Cluster includes the type strain of the named species.

Strains of the buccae and ZP complexes gave heavily staining high-mol.-wt (97.4-116 kDa) bands in SDSPAGE, produced propionic acid, acid from pentose sugars and gave heavy growth in FAB and large mucoid colonies on $\mathrm{BM}$, in contrast to those of the DB and OV complexes to the rear and right of fig. 3 . The sole exception was the $P$. oris group of pentosefermenting strains, an outlying cluster of the OV complex. The ZP and buccae complexes were similar in showing early strong fermentation of a broad range of sugars, but differed in the range, speed and strength of enzyme reactions, with the buccae complex showing much lower activity. The ZP complex strains produced large amounts of phenylacetic acid, a property shared only by $P$. loescheii.

\section{The OV complex}

Strains similar to $P$. oris predominated in CTRP clusters N-P and PMS clusters 8b, 15 and 16, appearing as a tight cluster beyond the right-hand edge of the OV complex in fig. 4. They were distinct from other OV complex strains, being pentose positive (table III) and showed low similarities in the PMS similarity matrix and dendrogram (fig. 2). Like $P$. oulora, and, to a lesser extent, $P$. buccalis, these strains showed limited compositional and biochemical similarity to the main OV complex.

Strains of $P$. oralis were distinct from those of $P$. oris in CTRPs (cluster F) and PMS (clusters 5, 8a and 9a). However, two strains showed ambivalent cluster membership, one with CTRPs indicative of $P$. oris but PMS indicative of $P$. oralis, and the other vice versa. P. oralis formed two distinct tight clusters within the OV complex, distinguished by $\alpha$-mannosidase activity in CTRPs. These species were homogeneous and distinct in SDS-PAGE. ${ }^{36}$

Strains similar to $P$. veroralis were found in CTRP clusters $G$ and $H$, and PMS clusters 1b, 1c, 10a and $10 \mathrm{~b}$. In the ordination diagram, strains fell within the OV complex as four separate clusters. Previous SDSPAGE studies ${ }^{36}$ had shown these strains to be heterogeneous, dividing them into subgroups A-E. PMS showed a similar division, but placed one member of $P$. veroralis $\mathrm{D}$ with strains of $P$. veroralis $\mathrm{A}$, and the other with strains of $P$. veroralis $\mathrm{C}$. These subgroups showed small differences in CTRPs (table III), the strains of $P$. veroralis $B$ being the most readily 
Table III. Conventional test reaction patterns

\begin{tabular}{|c|c|c|c|c|c|c|c|c|c|c|c|c|c|c|c|c|c|c|c|c|c|c|c|c|c|c|c|c|}
\hline \multirow[b]{2}{*}{ Cluster } & \multicolumn{28}{|c|}{ Typical reactions in conventional tests* } \\
\hline & 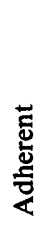 & 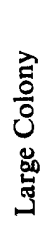 & 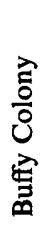 & 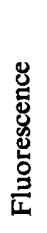 & 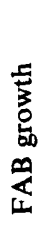 & 黑 & 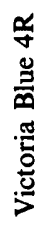 & 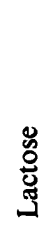 & $\frac{\mathscr{E}}{\grave{X}}$ & 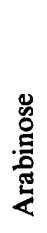 & 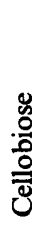 & $\frac{\sqrt[5]{3}}{\sqrt[\pi]{\pi}}$ & 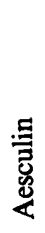 & 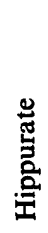 & $\begin{array}{l}\text { 吾 } \\
\text { 吾 } \\
\text { ஸ́ }\end{array}$ & 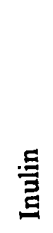 & $\frac{5}{x}$ & 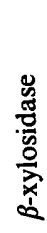 & 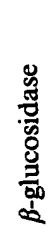 & 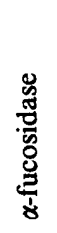 & 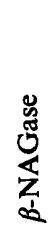 & 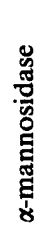 & $\begin{array}{l}0 \\
\frac{2}{Z}\end{array}$ & 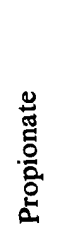 & 苞 & 离 & 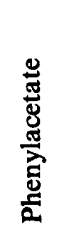 & 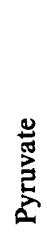 \\
\hline Buccae complex & & & & & & & & & & & & & & & & & & & & & & & & & & & & \\
\hline P. buccae ${ }^{\dagger}$ & - & + & + & - & + & - & + & + & + & + & + & + & + & - & + & + & + & + & + & - & - & - & + & $\mathbf{T}$ & $\mathbf{T}$ & $\mathrm{L}$ & - & - \\
\hline $\begin{array}{l}\text { Undesignated IIB } \\
\text { OV complex }\end{array}$ & + & + & + & - & + & + & - & + & + & + & + & + & + & - & + & + & - & + & + & + & + & + & + & - & $\mathbf{T}$ & $\mathrm{L}$ & - & - \\
\hline$P$. disiens & - & + & - & + & $\mathrm{v}$ & $\mathrm{v}$ & + & - & - & - & - & - & - & + & + & - & - & - & - & - & - & $\mathrm{v}$ & - & - & $\mathbf{T}$ & $\mathrm{L}$ & - & - \\
\hline$P$. oralis & - & - & - & - & - & - & + & + & - & - & + & + & + & - & + & $\mathrm{v}$ & - & $\mathbf{v}$ & + & + & + & $\mathrm{v}$ & + & - & - & $\mathrm{T}$ & $\mathrm{T}$ & - \\
\hline P. veroralis A & - & - & - & + & - & - & $\mathbf{v}$ & + & - & - & $\mathrm{v}$ & - & + & - & d & $\mathrm{v}$ & $\mathbf{v}$ & - & + & + & + & + & + & - & - & $\mathrm{T}$ & - & + \\
\hline P. veroralis B & - & - & - & + & - & - & + & + & - & - & v & - & + & - & + & + & $\mathrm{v}$ & - & + & + & + & + & + & - & $\mathrm{T}$ & $\mathrm{L}$ & - & $\mathrm{v}$ \\
\hline P. veroralis $\mathrm{C}$ & - & - & - & + & - & $\mathrm{v}$ & $v$ & + & - & - & + & - & + & - & + & - & - & - & + & + & + & $\mathrm{v}$ & + & - & $\mathbf{T}$ & $\mathrm{T}$ & - & - \\
\hline P. veroralis $\mathrm{E}$ & - & - & - & + & - & - & - & + & - & - & + & - & + & - & + & - & + & - & + & + & + & + & + & - & - & $\mathbf{T}$ & - & + \\
\hline P. buccalis & - & - & - & - & - & + & + & + & - & - & + & - & + & + & - & + & - & - & + & + & + & + & + & - & $\mathbf{T}$ & L & - & + \\
\hline P. loescheii & - & + & + & + & + & - & + & - & - & - & + & - & + & - & + & - & + & - & + & + & + & - & + & $\mathrm{L}$ & $\mathrm{L}$ & $\mathbf{L}$ & $\mathbf{L}$ & - \\
\hline Undesignated IXA & - & - & - & + & - & - & - & + & - & - & - & - & - & - & - & - & - & - & - & + & + & - & $\mathbf{v}$ & - & $\mathrm{T}$ & L & - & - \\
\hline $\begin{array}{l}P . \text { melaninogenica } \\
\text { OV complex outliers }\end{array}$ & - & - & - & + & - & - & + & + & - & - & - & - & - & - & + & - & - & - & - & + & + & - & + & - & $\mathrm{T}$ & L & - & - \\
\hline P. oulora & - & - & - & - & - & - & - & + & - & - & - & - & - & - & - & - & - & - & - & - & + & + & + & $\mathrm{L}$ & - & $\mathrm{T}$ & - & $\mathbf{v}$ \\
\hline $\begin{array}{l}P . \text { oris } \\
\text { DB complex }\end{array}$ & - & - & - & $\mathrm{v}$ & - & - & $v$ & + & + & + & + & + & + & - & $\mathrm{v}$ & - & - & $\mathrm{v}$ & + & + & + & v & + & $\mathbf{T}$ & - & $\mathrm{T}$ & - & - \\
\hline P. bivia & - & + & - & + & + & $v$ & + & + & - & - & - & - & - & + & + & - & - & - & - & + & $\mathrm{v}$ & $\mathrm{v}$ & + & - & $\mathbf{L}$ & $\mathrm{L}$ & - & - \\
\hline P. denticola & - & + & - & $\mathrm{v}$ & + & + & $\mathrm{v}$ & + & - & - & - & - & + & v & + & + & - & - & + & + & $\mathbf{v}$ & + & + & - & $\mathrm{T}$ & $\mathrm{L}$ & - & - \\
\hline P. corporis & + & + & + & - & + & + & + & - & - & - & - & - & - & + & + & - & - & - & - & - & - & - & - & - & $\mathbf{L}$ & $\overline{\mathrm{L}}$ & $\mathrm{T}$ & - \\
\hline $\begin{array}{l}P \text {. intermedia } \\
\text { ZP complex }\end{array}$ & + & + & + & - & + & $\mathbf{v}$ & - & - & - & - & - & - & - & - & + & $\mathrm{v}$ & - & - & - & + & - & - & - & - & $\mathrm{L}$ & $\mathrm{L}$ & - & - \\
\hline P. zoogleoformans & + & + & + & - & + & $\mathbf{v}$ & - & + & + & + & $t$ & + & + & - & $\mathrm{v}$ & + & - & $v$ & + & + & + & + & + & $\mathrm{L}$ & $\mathbf{L}$ & $\mathbf{L}$ & $\mathrm{T}$ & - \\
\hline B. $(P$.$) pentosaceus$ & - & + & + & - & + & - & + & + & + & + & + & + & + & - & + & + & - & - & + & + & + & - & + & $\mathbf{L}$ & $\mathrm{T}$ & $\mathrm{L}$ & $\mathrm{T}$ & - \\
\hline
\end{tabular}

* Test reactions are noted as follows: + , positive; - , negative; $v$, variable; $\mathrm{T}$, trace; $\mathrm{L}$, large amounts.

$\dagger$ Includes all strains of $P$. buccae A, P. buccae B and B. (P.) capillus.

The following tests yielded almost uniform results, giving good discrimination for the few exceptions noted: pigment $-(P$. loescheii, $P$. corpora and $P$. intermedia +$)$; short non-pleomorphic bacilli- $(P$. oris +$)$; indole $-(P$. loescheii $\mathrm{v}, P$. intermedia +$)$; rhamnose $-(P$. buccae $\mathrm{v})$; sucrose $+(P$. disiens, $P$. bivia and $P$. corporis -$) ; \beta$-glucuronidase $-(P$. oris and $P$. zoogleoformans,$+ B$. $(P$. $)$ pentosaceus $v) ; \alpha-$ galactosidase $+(P$. corpora,$- P$. intermedia $\mathrm{v})$; unidentified peak at retention time $15-16$ min $\mathrm{T}(P$. oralis,$- P$. veroralis subgroup A v, $P$. loescheii $\mathrm{L})$. All strains hydrolysed indoxyl acetate.

distinguishable in their resemblance to $P$. buccalis (CTRP cluster I) rather than $P$. veroralis (CTRP clusters $\mathrm{H}$ and $\mathrm{G}$ ). After prolonged incubation, colonies with a central grey-pigmented region were always produced by subgroups $\mathrm{C}-\mathrm{F}$, rather variably by subgroup A, but not by subgroup B. The two collection strains, which were distinct from all subgroups in SDS-PAGE ${ }^{36}$ clustered with subgroup B in PMS.

The single strain of $P$. melaninogenica (PMS cluster 10c) was biochemically similar to the group of nonpigmented strains termed undesignated IXA in our previous study ${ }^{36}$ and also found in CTRP cluster A. However, these undesignated strains were distinct in SDS-PAGE ${ }^{36}$ and PMS (cluster la), forming a tight group at the lower left of the OV complex, with the strain of $P$. melaninogenica positioned well above them. They were highly fastidious and oxygen sensitive, producing tiny deep red fluorescent colonies on BM-KV agar, in contrast to the larger, pink fluorescent colonies of the less fastidious P. melaninogenica. Other distinguishing features were production of acid from starch and tolerance of Victoria Blue (table III).
The single strain of $P$. loescheii (CTRP cluster T, PMS cluster 11) also appeared close to this cluster of undesignated strains in the ordination diagram, but was distinct in CTRPs, SDS-PAGE and PMS. The single strain of $P$. buccalis (CTRP cluster J, PMS cluster 21) was distinct from $P$. veroralis and $P$. oralis in CTRPs, SDS-PAGE and PMS, and was a close outlier of the OV complex.

The single strain of $P$. oulora (CTRP cluster J, PMS cluster 21) lay to the front and above the OV complex, and appeared to be a distant outlier in CTRPs and PMS. The two strains of $P$. disiens (CTRP cluster D, PMS cluster 2) clustered at the upper centre of the OV complex in the tight PMS cluster 12a. The $P$. disiens strains were also distinct in SDS-PAGE. ${ }^{36}$

\section{The buccae complex}

Strains similar to the collection strains of $P$. buccae formed two groups: (a) the main cluster of strains in CTRP cluster $\mathrm{K}$ that were also members of PMS group $3 a, 3 b$ and $4 a$; (b) strains of CTRP cluster $K$ 


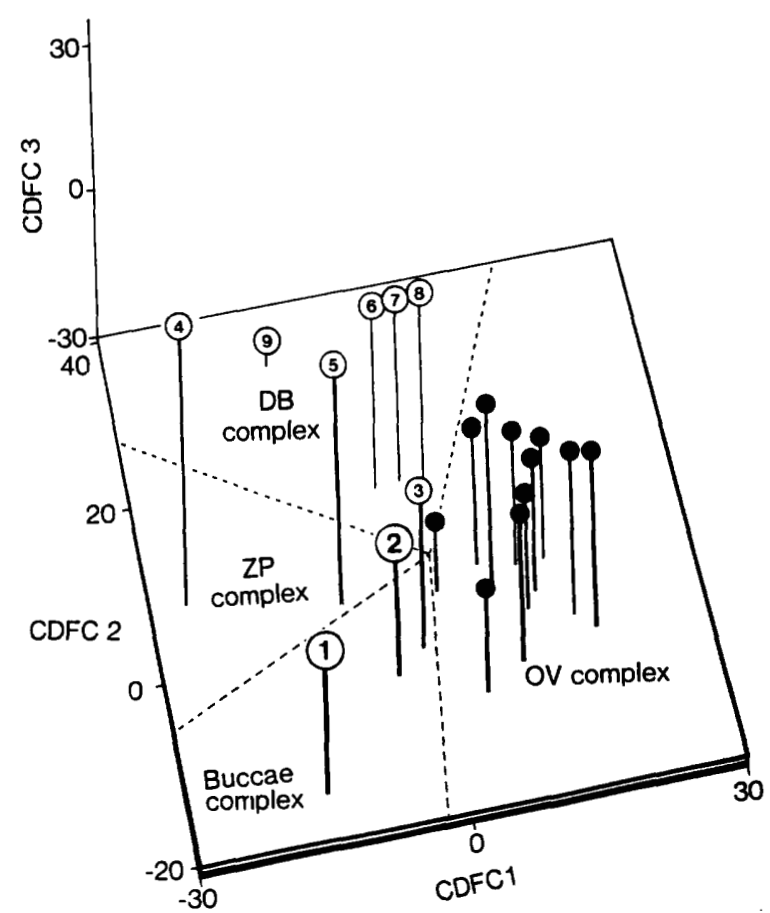

Fig. 3. An ordination diagram illustrating $57 \%$ of the strain discrimination achieved in PMS. Mean group points are plotted as a pseudo-three-dimensional scattergram on statistically derived axes (see Materials and methods). The straight line distance between any pair of points is a measure of the significance of the difference between their spectra. The buccae complex: $1, P$. buccae $\mathrm{b} ; 2, P$. buccae a; 3, undesignated IIb. The ZP complex: $4, P$. zoogleoformans; 5, B. (P.) pentosaceus. The DB complex: 6, $P$. bivia; $7, P$. denticola $; 8, P$. corporis, $9, P$. intermedia. Groups within the $\mathrm{OV}$ complex are represented by filled circles, and are shown in detail in fig. 4 .

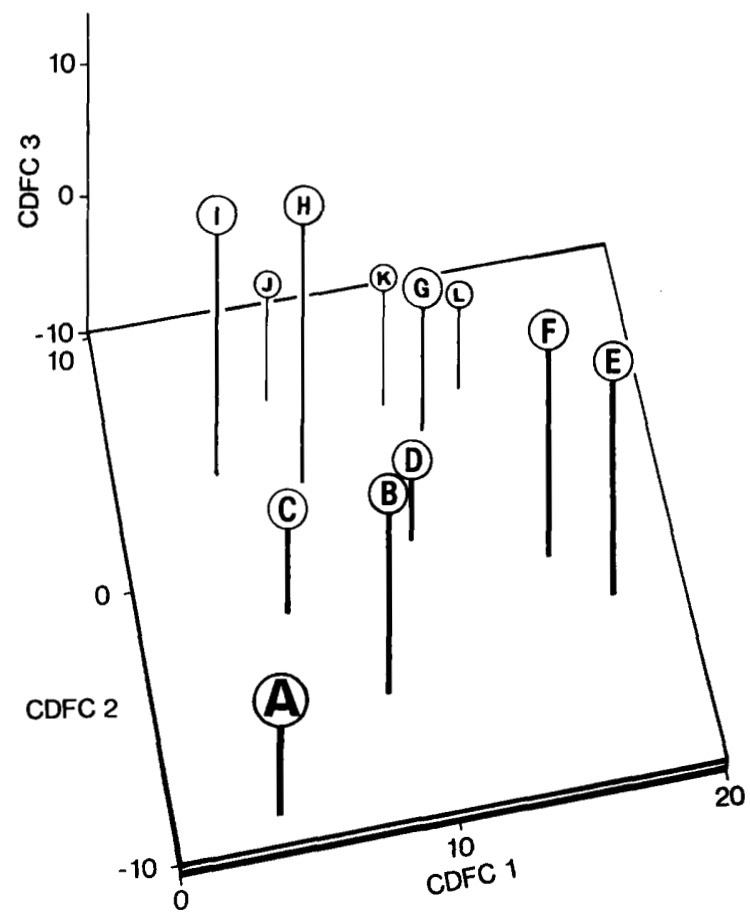

Fig. 4. An ordination diagram illustrating the discrimination between members of the OV complex in PMS. Mean group points are plotted in this enlargement of the OV complex region of fig. 3. $\mathbf{A}$, $P$. buccalis; B, $P$. oralis; C, undesignated IXA; D, $P$. veroralis subgroup $\mathrm{C} ; \mathbf{E}, P$. oris $; \mathbf{F}, P$. veroralis subgroup $\mathbf{A} ; \mathbf{G}, P$. disiens $; \mathbf{H}$, $P$. melaninogenica; $\mathbf{I}, P$. loescheii $; \mathbf{J}, P$. veroralis subgroup $\mathbf{B} ; \mathbf{K}, P$. veroralis subgroup $\mathrm{D} ; \mathbf{L}, P$. oulora. that were also members of PMS cluster 14. Although group $b$ strains were indistinguishable from group $a$ in CTRPs, they showed atypical patterns in SDS-PAGE, lacking one major protein band at $97-116 \mathrm{kDa}{ }^{36}$ The single strain of $B .(P$.$) capillus was indistinguishable$ from the main cluster of $P$. buccae in PMS, CTRPs and SDS-PAGE.

A further group comprised strains of CTRP cluster $\mathrm{L}$ that were also members of PMS cluster 7, and which were members of undesignated cluster IIB in our previous studies. ${ }^{35,36}$ These strains were similar to $P$. zoogleoformans in colony morphology, but more similar to P. buccae in PMS. They were homogeneous and distinct from P. buccae in CTRPs (table III) and SDS-PAGE.

\section{The DB complex}

With the exception of $P$. denticola, strains of this group showed little activity in the tests for enzyme activity. Strains of $P$. bivia were distinct from $P$. denticola in CTRP clusters $\mathrm{C}$ and I, respectively, but these two species formed a diffuse PMS cluster (clusters $12 a$ and $12 b$ ) above and to the rear of the OV complex in the ordination diagram. The group also appeared to contain the single strain of $P$. corporis (CTRP cluster $\mathrm{S}$, PMS cluster 13) in the ordination diagram which was, however, clearly distinct from the bivia-denticola cluster in the PMS similarity matrix. SDS-PAGE patterns for these species also showed them to be distinct and homogeneous. ${ }^{36}$ Strains of $P$. intermedia formed CTRP clusters $Q$ and $R$ and PMS cluster 22, shown as a tight cluster low down to the rear of the ordination diagram, and were gross outliers of the DB complex.

\section{The $Z P$ complex}

Other strains were scattered over the mid-left of the ordination diagram showing little tendency to cluster. These comprised strains of $P$. zoogleoformans (CTRP cluster M, PMS clusters 19, 20 and 23), and $B$. (P.) pentosaceus (CTRP cluster M, PMS clusters 18 and 20). In SDS-PAGE, both species appeared distinct but somewhat heterogeneous. ${ }^{36}$

\section{Discussion}

Many facets of the CTRP and PMS classifications coincided. Clustering in the PMS and CTRP classifications disagreed markedly for only seven strains, $6 \%$ of the strain collection. PMS distinguished two subgroups of $P$. oralis, differing slightly in composition and in $\alpha$-mannosidase activity, and showed considerable compositional heterogeneity in strains representing $P$. zoogleoformans and $B$. $(P$.) pentosaceus; CTRP and SDS-PAGE results for the three species suggested some heterogeneity but not to the extent 
found in PMS. These were the only areas of disagreement between PMS and the other test systems.

The genus was divided into four broad groups of species in PMS. The P. buccae complex comprised two clusters of this species plus a group of undesignated strains. The OV complex comprised the four clusters of $P$. veroralis, $P$. oralis, $P$. disiens, $P$. melaninogenica, $P$. loescheii, $P$. buccalis and undesignated IXA, with $P$. oris and $P$. oulora as outliers. The position of $P$. oris, albeit as an extreme outlier of this complex, is anomalous in view of its similarity to other complexes in pentose fermentation and other properties. This species has no proteinaceous $\mathrm{S}$ layer overlying its wall peptidoglycan, ${ }^{44}$ like species of the OV complex, but unlike species of the other pentose-fermenting complexes; the compositional difference may explain the anomalous position of $P$. oris in the PMS classification. Another complex comprised $P$. bivia, $P$. denticola, $P$. intermedia and $P$. corporis, and the fourth comprised $P$. zoogleoformans and $B$. $(P$.) pentosaceus.

These four groups of species differed in resistance to lysis, SDS-PAGE, colony morphology, pentose fermentation and production of phenylacetic acid. Detailed chemotaxonomic investigation of compositional differences between these broad groups might well be profitable, particularly as resistance to lysis may well reflect differences in cell wall composition. The OV complex appeared as a central group; compositional differences between this "core" and other groups to the periphery almost invariably correlated with pentose positivity. This observation may have implications relevant to phylogeny and ecology within the genus.

Within these broad groups, species that were consistently homogeneous and distinct in PMS, SDSPAGE and CTRPs were: $P$. oris, $P$. bivia plus $P$. denticola, and $P$. intermedia. Species represented by only a single strain, but clearly distinct from other species in all characterisation systems were: $P$. melaninogenica, $P$. loescheii, $P$. oulora and $P$. corporis. The inability of all test systems to distinguish the single strain representing $B$. $(P$.) capillus from the main group (and references strain) of $P$. buccae supports DNA hybridisation results which suggest that these species names are synonymous. ${ }^{34}$

However, results in all test systems suggested that the two reference strains representing $B$. $(P$.) pentosaceus (including the type strain, NCDO 2353, as the clone NP 333) were distinct from $P$. buccae, contradicting DNA hybridisation results which showed high genetic similarity between $B$. (P.) pentosaceus and $P$. buccae and the suggestion that these species are synonymous. ${ }^{34}$ The single strain of $B$. (P.) pentosaceus investigated in DNA hybridisation, the type strain NCDO 2353, is said to be a clone of the Virginia Polytechnic strain NP 333, included in our studies. The wide differences in enzyme patterns, fatty acid pro- duction, and in composition as revealed by PMS and SDS-PAGE, seem incompatible with the published DNA hybridisation results. Studies of a larger number of $B$. $(P$.) pentosaceus strains in DNA hybridisation and other systems may be required to resolve this anomaly.

For P. buccae and P. veroralis, several PMS clusters showed strain membership equivalent to a single CTRP cluster. However, these PMS subdivisions of the CTRP cluster membership were closely mirrored in the subdivisions suggested by SDS-PAGE results. Whether these subdivisions should be regarded as species or subspecies cannot be judged from these results alone. PMS classifications of other genera have occasionally yielded clusters that subdivided recognised species, e.g., separating Listeria monocytogenes into two PMS clusters. ${ }^{43}$ However, SDS-PAGE showed clear differences between the PMS subgroups of Prevotella spp., ${ }^{36}$ and the differences in CTRPs between the subgroups of $P$. veroralis support this division. DNA hybridisation studies of these two species might be helpful.

PMS confirmed the compositional homogeneity and the distinct nature of the two undesignated clusters which were previously differentiated from known species on the basis of CTRPs and SDS-PAGE. ${ }^{35,36}$ The level of differences in all test systems suggest that these undesignated groups may represent previously unreported species groups.

The importance of these results is to draw attention to the possibilities of heterogeneity within the currently accepted species, and of new centres of variation within the genus, providing a framework within which slower techniques with low throughput, such as DNA hybridisation, might be usefully directed.

PMS readily distinguished several groups that were difficult to differentiate in conventional tests. Particular examples of pairs of species showing greater differences in PMS than CTRPs include: $P$. denticola and $P$. melaninogenica; $P$. intermedia and $P$. corporis; and $P$. bivia and $P$. disiens. Such good discrimination in an otherwise difficult area suggests a role for PMS in identification of these anaerobes. PMS is a rapid technique, with low running costs that might well be suitable for laboratories undertaking routine identification of larger numbers of strains which present such difficulties. At present, it is necessary to accompany each batch of test strains with a calibration set of standard strains, ${ }^{45}$ but this is not a problem because of the speed, throughput and low sample cost of PMS. The potential of PMS in identification laboratories is illustrated by the early work of Wieten and his colleagues on mycobacteria. ${ }^{45,46}$

We thank Perkin Elmer, the trustees of the United Sheffield Hospitals Fund, Horizon Instruments and Trent Region Research Committee, for their generous assistance in funding, loans of equipment and other help for our work in the pyrolysis field. 


\section{References}

1. Shah HN, Collins MD. Prevotella, a new genus to include Bacteroides melaninogenicus and related species formerly classified in the genus Bacteroides. Int $J$ Syst Bacteriol 1990; 40: 205-208.

2. Finegold SM, Barnes EM. Report of the ICSB Taxonomic Subcommittee on Gram-negative Anaerobic Rods. Proposal that the saccharolytic and asaccharolytic strains at present classified in the species Bacteroides melaninogenicus (Oliver and Wherry) be reclassified in two species as Bacteroides melaninogenicus and Bacteroides asaccharolyticus. Int J Syst Bacteriol 1977; 27: 388-391.

3. Slots J. Microflora in the healthy gingival sulcus in man. Scand J Dent Res 1977; 85: 247-254.

4. Duerden BI. The isolation and identification of Bacteroides spp. from the normal human gingival flora. $J$ Med Microbiol 1980; 13: 89-101.

5. Socransky SS, Gibbons RJ, Dale AC, Bortnick L, Rosenthal E, MacDonald JB. The microbiota of the gingival crevice area of man. I. Total microscopic and viable counts and counts of specific organisms. Arch Oral Biol 1963; 8: 275-280.

6. Slots J. Subgingival microflora and periodontal disease. J Clin Periodont 1979; 6: 351-382.

7. Slots J. Importance of black pigmented Bacteroides in human periodontal disease. In: Genco RJ, Mergenhagan SE (eds) Host-parasite interaction in periodontal diseases. Washington DC, American Society for Microbiology. 1982: $27-45$.

8. Duerden BI, Goodwin L, O'Neil TCA. Identification of Bacteroides species from adult periodontal disease. $\mathrm{J} \mathrm{Med}$ Microbiol 1987; 24: 133-137.

9. van Steenbergen TJM, van Winkelhoff AJ, van der Velden U, de Graaff J. Taxonomy, virulence and epidemiology of blackpigmented Bacteroides species in relation to oral infections. Infection 1989; 17: 194-196.

10. Finegold SM. Intra-abdominal, genitourinary, skin and soft tissue infections due to non-sporing anaerobic bacteria. In: Phillips I, Sussman M (eds) Infection with non-sporing bacteria. Edinburgh, Churchill Livingstone. 1974: 160-182.

11. Duerden BI. The identification of gram-negative anaerobic bacilli isolated from clinical infections. $J$ Hyg $1980 ; 84$ : 301-313.

12. Duerden BI. Infections due to gram-negative non-sporing anaerobic bacilli. In: Wilson GR et al. (eds) Topley and Wilson's Principles of bacteriology, virology and immunity, 7th edn, vol 3. London, Edward Arnold. 1984: 311-326.

13. Ingham HR, Selkon JB, Roxby CM. Bacteriological study of otogenic cerebral abscesses: chemotherapeutic role of metronidazole. $B M J 1977 ; 2$ : 991-993.

14. Brusi $T$, Luckhaupt $H$. Anaerobic infections in ulcerating tumors of the head and neck. Laryngol Rhinol Otol 1986; 65: $65-68$.

15. Brook I. Direct and indirect pathogenicity of anaerobic bacteria in respiratory tract infections in children. Adv Pediatr $1987 ; 34: 357-377$.

16. Finegold SM. Anaerobic bacteria in human disease. New York, Academic Press. 1977.

17. Shah HN, Collins MD. Proposal to restrict the genus Bacteroides (Castellani and Chalmers) to Bacteroides fragilis and closely related species. Int J Syst Bacteriol 1989; 39: 85-87.

18. Loesche WJ, Socransky SS, Gibbons RJ. Bacteroides oralis proposed new species isolated from the oral cavity of man. $J$ Bacteriol 1964; 88: 1329-1337.

19. Holbrook WP, Duerden BI. A comparison of some characteristics of reference strains of Bacteroides oralis with Bacteroides melaninogenicus. Arch Oral Biol 1974; 19: 1231-1235.

20. van Steenbergen TJM, Shah HN, Hardie JM, de Graaf J. Taxonomic studies on Bacteroides oralis. Antonie van Leeuwenhoek 1980; 46: 231 .

21. Holdeman LV, Johnson JL. Description of Bacteroides loescheii sp. nov. and emendation of the descriptions of Bacteroides melaninogenicus (Oliver and Wherry) Roy and Kelly 1939 and Bacteroides denticola Shah and Collins 1981. Int J Syst Bacteriol 1982; 32: 399-409.
22. Gorbach SL, Menda KB, Thadepalli H, Keith L. Anaerobic microflora of the cervix in healthy women. Am J Obst Gynaecol 1973; 117: 1053-1055.

23. Masfari AN, Kinghorn GR, Duerden BI. Anaerobes in genitourinary infections in men. $B r J$ Vener Dis 1983; 59: 255-259.

24. Jones BM, Kinghorn GR, Duerden BI. An overview of the diagnosis and treatment of Gardnerella vaginalis- and Bacteroides associated vaginitis. Eur J Clin Microbiol 1982; 1: 320-325.

25. Piot $\mathbf{P}$, Van Dyck E, Godts $\mathbf{P}$, Vanderheyden $\mathbf{J}$. The vaginal microbial flora in non-specific vaginitis. Eur J Clin Microbiol 1982; 1: 301-306.

26. Holst E, Wathne B, Hovelius B, Mårdh PA. Bacterial vaginosus: microbiological and clinical findings. Eur J Clin Microbiol 1987; 6: 536-541.

27. Holdeman LV, Johnson JL. Bacteroides disiens sp. nov. and Bacteroides bivius sp. nov. from human clinical infections. Int J Syst Bacteriol 1977; 27: 337-345.

28. Holdeman LV, Moore WEC, Churn PJ, Johnson JL. Bacteroides oris and Bacteroides buccae, new species from human periodontitis and other human infections. Int J Syst Bacteriol 1982; 32: 125-131.

29. Shah HN, Collins MD. Bacteroides buccalis sp. nov., Bacteroides denticola sp. nov. and Bacteroides pentosaceus sp. nov., new species of the genus Bacteroides from the oral cavity. Zentralbl Bakteriol Hyg I Abt Orig C 1981; 2: 235-241.

30. Cato EP, Kelley RW, Moore WEC, Holdeman LV. Bacteroides zoogleoformans (Weinberg, Nativelle, and Prévot 1937) corrig., comb. nov.: emended description. Int J Syst Bacteriol 1982; 32: 271-274.

31. Watabe J, Benno Y, Mitsuoka T. Taxonomic study of Bacteroides oralis and related organisms and proposal of Bacteroides veroralis sp. nov. Int J Syst Bacteriol 1983; 33: 57-64.

32. Shah HN, Collins MD, Watabe J, Mitsuoka T. Bacteroides oulorum sp. nov., a nonpigmented saccharolytic species from the oral cavity. Int $J$ Syst Bacteriol 1985; 35: 193-197.

33. Kornman KS, Holt SC. Physiological and ultrastructural characterisation of a new bacteroides species (Bacteroides capillus) isolated from severe localised periodontitis. $J$ Periodont Res 1981; 16: 542-555.

34. Johnson JL, Holdeman LV. Bacteroides capillus Kornman and Holt and Bacteroides pentosaceus Shah and Collins, later synonyms of Bacteroides buccae Holdeman et al. Int J Syst Bacteriol 1985: 35: 114

35. Yousefi-Mashouf R, Duerden BI. An identification scheme for oral non-pigmented Prevotella (Bacteroides) species. Microbial Ecol Hlth Dis 1992; 5: 31-41.

36. Yousefi-Mashouf R, Eley A, Duerden BI. Characterisation of the genus Prevotella by polyacrylamide gel electrophoresis. J Med Microbiol 1992; 37: 83-90.

37. Gutteridge CS, Vallis l, MacFie HJH. Numerical methods in the classification of micro-organisms by pyrolysis massspectrometry. In: Goodfellow $\mathrm{M}$ et al. (eds) Computerassisted bacterial systematics. London, Academic Press. 1985: 369-401.

38. Magee JT. Whole organism fingerprinting. In : Goodfellow M, O'Donnell K (eds) The new bacterial taxonomy. London, Academic Press. 1992 (in press).

39. Holbrook WP, Ogston SA, Ross PW. A method for the isolation of Bacteroides melaninogenicus from the human mouth. $J$ Med Microbiol 1978; 11: 203-207.

40. Yousefi-Mashouf R, Duerden BI. An identification scheme for oral non-pigmented Bacteroides species. J Med Microbiol $1990 ; 33$ : ii.

41. Casals JB, Pringler N. Diagnostic tablets for bacterial identification. 1987. Rosco Diagnostica, Taastrup, Denmark.

42. Magee JT, Hindmarch JM, Bennett KW, Duerden BI, Aries RE. A pyrolysis mass spectrometry study of fusobacteria. $J$ Med Microbiol 1989; 28: 227-236.

43. Hindmarch JM, Magee JT, Hadfield MA, Duerden BI. A pyrolysis-mass spectrometry study of Corynebacterium spp. J Med Microbiol 1990; 31: 137-149.

44. Haapasalo M, Lounatmaa K, Ranta $H$, Shah H, Ranta $K$. Ultrastructure of Bacteroides capillus, B. buccae, B. pentosaceus, $B$. oris, $B$. oralis, B. veroralis, and pentose sugar- 
fermenting Bacteroides sp. from humans with periapical osteitis: occurrence of external proteinaceous cell wall layer. Int J Syst Bacteriol 1985; 35: 65-72.

45. Wieten G, Haverkamp J, Meuzelaar HLC, Engel HWB, Berwald LG. Pyrolysis mass spectrometry: a new method to differentiate between the mycobacteria of the 'Tuber- culosis complex' and other mycobacteria. J Gen Microbiol $1981 ; 122$ : 109-118.

46. Wieten G, Haverkamp J, Berwald LG, David HL. Classification and identification of Mycobacterium africanum by pyrolysis mass spectrometry. J Gen Microbiol 1983; 129: 3679-3688. 